\title{
Establecimientos Penitenciarios
}

\author{
Correctional facilities
}

\author{
Dra. M. $^{\text {a }}$ Nieves NAVARRO MOZO \\ va0411@hotmail.com
}

\begin{abstract}
Resumen: El subsiguiente documento es un análisis acerca del mundo penitenciario en general, de manera que primero, he escrito sobre la diferencia entre Derecho Penal, Derecho Procesal y Derecho Penitenciario en España, y a continuación he hecho un recorrido histórico acerca de las prisiones españolas; sin embargo, no he olvidado la cuestión del régimen penitenciario como algo básico, aunque también escribo de los grados en la prisión como un tema muy importante. Y finalmente hay una conclusión, que es significativa, la reeducación y reinserción del preso.
\end{abstract}

Abstract: The document below is an analysis about penitentiary world in general, so firstly, I have written about difference betwen criminal law, procedural law and penitentiary law in Spain, and then I make a historical path about the Spanish prison; however, I haven't forgotten the regime penitentiary topic like something basic, although I also write of degrees prison as very important topic. And finally there is a conclusion, that it's significant the prisoner reeducation and reintegration.

Palabras clave: Penitenciario, ley, español, grados penitenciarios, reeducación, reinserción.

Keywords: Penitentiary, law, Spanish, degrees, prison, reeducation, reintegration.

\section{Sumario:}

\section{Evolución.}

II. Grados penitenciarios y régimen penitenciario.

2.1. Los ficheros de internos de especial seguimiento. 
III. Reeducación y reinserción.

IV. Derechos de los internos. Referencia a las agresiones a funcionarios.

V. Referencias bibliográficas y otras fuentes.

Recibido: septiembre 2021.

Aceptado: noviembre. 
Como hipótesis contrastadas a esta exposición dentro del entorno penitenciario en España, está la evolución de los establecimientos penitenciarios que discurre paralelamente a su mejora, planteamiento sobre el régimen de vida y los grados penitenciarios, o los derechos que mantienen los reclusos, con especial referencia al derecho a la vida e integridad física y moral.

\section{EVOLUCIÓN}

Siendo las cárceles españolas el tema que nos ocupa, previamente esto nos mueve a explicar como el Derecho Penitenciario está incurso en el ámbito de lo penal, de tal manera que es una desmembración del Derecho Penal o Ius Puniendi, siendo éste el que fija la pena, la cual es aplicada por los Jueces y Tribunales a través del Derecho Procesal Penal, y finalmente será mediante el Derecho Penitenciario cómo se ejecuten las penas privativas de libertad.

En España actualmente y con independencia de nuestra Carta Magna la Constitución Española de 1978, tenemos que el paraguas legal del sistema penitenciario está en la LOGP 1/1979, de 26 de septiembre, cuyo padre y artífice fue el jurista don Carlos García Valdés, así como el RP de su desarrollo aprobado por RD 190/1996, de 9 de febrero, amén de las normas internacionales como las Reglas Mínimas de Ginebra para el tratamiento de los reclusos de 1955 o las Reglas Mínimas para el tratamiento de los detenidos adoptadas por el Consejo de Europa en el año 1973.

En el Estado Español situándonos históricamente hacia el siglo XIX, sobre la evolución de los establecimientos penitenciarios, éstos están ubicados en el orden militar, y son por ende militares los que rigen estas prisiones, siendo considerados los reclusos como soldados de servicio. Fue un hito histórico la Ordenanza General de Presidios del Reino del año 1834, que representa el comienzo del cambio para que las cárceles militares pasen a cárceles civiles. Se pretende de facto que el carácter militar sea para los llamados arsenales y para los pequeños centros carcelarios situados en África; en este contexto, y aún cuando a nivel de régimen interno se continúa con la rígida disciplina militar, sin embargo a nivel externo dependen del Ministerio de Fomento ${ }^{1}$.

\footnotetext{
${ }^{1}$ SERRANO PATIÑO, J. V., «Una reflexión histórica desde una perspectiva penitenciaria» [en línea], Estudios de Historia de España 17, 2015. Disponible en:
} 
Al hilo de todo esto, cabe referirse que hacia el año 1949 con la Ley de Prisiones se van a hacer centros penitenciarios bajo la dirección del Ministerio de la Gobernación y centros penitenciarios militares bajo la dirección del Ministerio de la Guerra, y consiguientemente cabe referirse a la diferencia entre Derecho Penitenciario Militar y Derecho Penitenciario Civil ${ }^{2}$.

El concepto de delincuente en la época de finales del $\mathrm{S}^{\mathrm{o}}$ XIX y primera mitad del $\mathrm{S}^{\circ} \mathrm{XX}$, está imbuida de una corriente positivista de la que deriva el movimiento científico de la antropología criminal, cuyo exponente lo tenemos en Rafael Salillas, figura no siempre comprendida, y seguidor de Lombrosso aunque en sus teorías criminológicas le mueve el aspecto psicológico de la persona que delinque más que el aspecto propiamente fisiológico ${ }^{3}$.

También cabe destacar el nombre de Fernando Cadalso, penitenciarista que institucionaliza el sistema progresivo en los establecimientos penitenciarios, el cual ha de perdurar hasta la aprobación de la Ley Orgánica General Penitenciaria en el año 1979, y al que me referiré más adelante.

Si nos circunscribimos a la idea de castigo en sí misma, habría que dejar meridianamente diferenciado lo que son las penas privativas de libertad de las denominadas medidas de seguridad, de tal manera que las primeras, es decir las penas, tienen su justificación en la comisión de un hecho delictivo tipificado por ley y pudiendo ser culpables una o varias personas que serán sancionadas, mientras que las segundas, es decir las medidas de seguridad en las que se busca la prevención, se nutren del elemento peligrosidad, y se aplica a aquellos sujetos inimputables que cometen un ilícito penal.

\section{GRADOS PENITENCIARIOS Y RÉGIMEN PENITENCIARIO}

En otro orden de cosas, hay que hacer referencia a las reglas organizativas de la vida en orden y paz del recinto carcelario, y que unas veces emanan del Ordenamiento Jurídico y en otras ocasiones se trata de reglas no escritas provenientes de los propios reclusos, y esto se denomina régimen penitenciario, que abarca aspectos cotidianos de la convivencia en las prisiones, como son,

\footnotetext{
http://bibliotecadigital.uca.edu.ar/repositorio/revistas/reflexion-historica-perspectivapenitenciaria.pdf [Fecha de consulta: 08-12-2020].

${ }^{2}$ GARCÍA VALDÉS, C., $<<$ Derecho Penitenciario Militar: una aproximación histórica $>>$ en Anuario de Derecho Penal y Ciencias Penales, Tomo 39, Fasc/ (1986) 774 y ss.

${ }^{3}$ FERNÁNDEZ RODRÍGUEZ, M.D., El pensamiento penitenciario y criminológico de Rafael Salillas, Santiago de Compostela, Secretariado de Publicaciones de la Universidad de Santiago de Compostela, 1976, pp. 206 y ss.
} 
cuestiones de salud, ejercicio del culto, asuntos laborales, cauces para solventar quejas, sistema de visitas, enseñanza o formación, y otros, siendo en definitiva un modo de organizar el micro mundo que se crea en el interior de los muros, para que las relaciones interpersonales y demás temas que afecten al interno, se resuelvan desde el pragmatismo y las normas, lejos de un posible arbitrio de la Administración.

Este régimen varía en función del grado penitenciario, ya que no todos los presos se sitúan dentro del mismo nivel de clasificación, de tal manera que existen tantos regímenes penitenciarios como grados de clasificación, y así podemos establecer tres grupos de mayor a menor libertad de movimientos, como son: Para los internos clasificados en tercer grado, dirigido a penados y no a preventivos, se articula un modelo de régimen abierto o de semi libertad, en el que se aflojan las necesidades de control, pues es un paso más hacia la reinserción social, y por consiguiente el recluso puede hacer vida fuera de la cárcel aunque regrese para pernoctar. La manera de acceder a esta clasificación es previo informe de la Junta de Tratamiento que eleva al Juez para que decida. Para los internos clasificados en segundo grado, se articula un modelo de régimen denominado ordinario que es el mayoritariamente común, aplicable a su vez a internos aún sin clasificar y que en tanto se resuelva esta situación estarán aquí ubicados; se destinará también a las personas detenidas y a los internos preventivos. // Finalmente, están los internos clasificados en primer grado, para los que se va articular un modelo de régimen cerrado, más restrictivo que el anterior, pues está dirigido a aquellos sujetos en los que concurran o bien circunstancias que entrañen mayor peligrosidad y por ello se acentúan las medidas de seguridad, o bien para aquellas personas que no se adapten al régimen ordinario. Y dentro de este grado cabe desglosar varias cotas de severidad, y así nos encontramos:

- Un nivel cerrado strictu sensu.

- Unos departamentos especiales para internos extremadamente peligrosos o que hayan sido sujetos activos de altercados muy graves con riesgo evidente para la vida e indemnidad física de otros o que hayan sido inductores de estos altercados.

- Y los controvertidos ficheros de internos de especial seguimiento ${ }^{4}$.

\footnotetext{
${ }^{4}$ SOLAR CALVO, P., «Límites al fichero FIES en la nueva LOPD: una oportunidad para el cambio», Legal Today, Portal Jurídico de Thomson Reuters, 15-03-2019, Límites al fichero FIES en la nueva LOPD: una oportunidad para el cambio -Información jurídica, noticias y artículosLegal Today; consultado: 11-12-2020.
} 


\subsection{Los ficheros de internos de especial seguimiento}

Están recogidos en la Instrucción 21/1996 de 16 de diciembre de medidas de seguridad para internos de especial seguimiento, la cual se sustituye años después por la Instrucción 6/2006 de 22 de febrero, y ésta también años más tarde se sustituye por la Instrucción 12/2011 de 29 de julio. Pese a que durante años jurisprudencialmente estos FIES se aceptan, sin embargo por STS de 17/03/2009 se produce un cambio de tendencia, pues entiende el alto tribunal que estos ficheros llevan consigo una restricción de derechos para los presos incluidos en ellos y además se infringe la reserva de ley, por lo que en un intento de respetar el mandato recogido en el contenido de esta sentencia, se aprueba la antedicha Instrucción 12/2011 y se modifican algunos artículos del Reglamento Penitenciario, aunque aún así esto sigue siendo insuficiente al faltar rango legal. Doctrinalmente fue un asunto que suscitaba controversia y suspicacias, pues hasta la reforma del Reglamento Penitenciario por el RD 419/2011 de 25 de marzo, estos ficheros únicamente estaban contemplados en normas propias de la Administración Penitenciaria, pero hay que nombrar el art. 6-4 $\mathrm{RP}^{5}$ que permite a dicha Administración fijar ficheros para algunos reclusos con el propósito de mantener una normal convivencia carcelaria ${ }^{6}$. Resta añadir que en la actualidad los FIES no se refieren a una clasificación como tal sino que son una base de datos que aportan más información sobre las circunstancias que rodean la situación personal, procesal, penal y penitenciaria de algunos reclusos -con independencia del grado penitenciario en el que se encuentren-, pero aún así algunos entienden que estar incluso en un FIES acarrea un régimen penitenciario velado ${ }^{7}$.

Los internos pueden progresar en grado, pero cabe la opción de que una persona se encuentre en un grado penitenciario superior y a través de la regresión pase a un grado inferior. En relación a esto, no hay que olvidar que en el sistema penitenciario español impera la individualización científica cuyo precedente

5 Art 6-4 RP: "La Administración penitenciaria podrá establecer ficheros de internos que tengan como finalidad garantizar la seguridad y el buen orden del establecimiento, así como la integridad de los internos. En ningún caso la inclusión en dicho fichero determinará por sí misma un régimen de vida distinto de aquél que reglamentariamente corresponda".

${ }^{6}$ DE VICENTE MARTÍNEZ, R. et al., Derecho Penitenciario, Valencia, Edit. Tirant lo Blanch, 2015, pp. 296 y 297.

${ }^{7}$ RÍOS MARTÍN, J.C., «Los ficheros de internos de especial seguimiento», en Cuadernos de Derecho Penitenciario (Colegio de Abogados de Madrid), № 3 (1998).

ASOCIACIÓN PRO DERECHOS HUMANOS DE ESPAÑA, Informe sobre la situación de las prisiones en España, Madrid, Edit. Fundamentos, 1999, pp. 436 y ss.

CERVELLÓ DONDERIS, V., Derecho Penitenciario, Valencia, Edit. Tirant lo Blanch, 2016, pp. 250-253. 
lo encontramos en el sistema progresivo ${ }^{8}$, de forma que en éste se buscaba atenuar la intensidad de la sanción en función de los períodos por los que habría de pasar el reo, y en cada uno de ellos accedería a un régimen de vida distinto que le iría preparando hasta su libertad, de tal manera que paralelamente a ello iría recuperando los derechos que se le limitaron por la condena, a lo que se añadía la exigencia de estar obligatoriamente un tiempo en cada uno de los grados. Sin embargo el actual sistema de individualización científica, tras la reforma del Reglamento de Servicios de Prisiones de 1956 mediante el RD 2273/1977 de 29 de julio, deja atrás la rigidez del sistema progresivo para dar paso a un sistema más flexible, pues no contempla diferencias en función de las fases sino que lo hace en función de las circunstancias personales de cada recluso, que es conforme se aplicarán los distintos tratamientos, y así cabe concluir que se contemplan variedad de grados y de regímenes de vida ${ }^{9}$.

A propósito de lo que antecede, no hay que olvidar dejar constancia de un posiblemente denominado como cuarto grado, que es la llamada libertad condicional. Esta figura implica la suspensión de la condena privativa de libertad, por lo que el recluso pasa a una situación de libertad, sólo que sujeto a ciertas premisas de obligado cumplimiento que vienen fijadas por el Juzgado de Vigilancia Penitenciaria ${ }^{10}$.

\section{REEDUCACIÓN Y REINSERCIÓN}

Otro asunto que abordar y al que no puedo dejar pasar la ocasión de referirme, es al fin último de la prisión tal y como se concibe en España en estos momentos, y que no es otro que reeducar y reinsertar al delincuente una vez haya cumplido su pena y tenga que volver a vivir en una sociedad libre. Hay que intentar evitar el efecto de la prisionización, pues cuando una persona entra en la cárcel -y máxime si el cumplimiento de su pena conlleva un período muy largo de reclusión-, es fácil dejar parte de uno mismo fuera y pasar a adquirir hábitos y comportamientos propios de un recluso, y por tanto es muy importante para el éxito de esa reinserción que las necesidades primeras estén cubiertas, es decir que alguien espere fuera, tener un lugar donde vivir

${ }^{8}$ Art 72-1 LOG: "Las penas privativas de libertad se ejecutarán según el sistema de individualización científica, separado en grados, el último de los cuales será el de libertad condicional, conforme determina el Código Penal".

${ }^{9}$ FERNÁNDEZ BERMEJO, D., Individualización cientifica y tratamiento en prisión, Madrid, Gobierno de España - Ministerio del Interior - Secretaría General de Instituciones Penitenciarias, 2013, pp. 478 y ss.

${ }^{10}$ Hay referencias a esta figura penitenciaria en los Arts. 90 y $91 \mathrm{CP}$, así como en los Arts 192 - 201 RP, también se hace mención a la misma en la Disposición Adicional Quinta LOPJ, y en el Art 72 LOGP. 
y una ocupación a la que dedicarse, pues eso es equivalente a tener seguridad. La persona suele salir con una baja consideración de sí misma, pudiendo llegar a creer que está estigmatizada pues algo la delata como delincuente, por lo que cualquier acto que tenga que hacer por insignificante que sea, le podrá parecer inasumible, y esto precisamente es lo que hay que evitar para así no cometer los mismos errores que le condujeron a prisión; no debería ser que la salida de la cárcel, se convierta en algo negativo, ya que dentro del centro penitenciario puede haber tenido su tratamiento individualizado para corregir lo que sea preciso, y esto junto con los apoyos externos serán garantía de lograr una vida digna lejos del delito ${ }^{11}$.

\section{DERECHOS DE LOS INTERNOS. REFERENCIA A LAS AGRE- SIONES A FUNCIONARIOS}

Para concluir, está la cuestión de los derechos de los internos penitenciarios, pues la vida del penado implica el cumplimiento de determinada pena, lo cual no es óbice para que sea respetado en el ejercicio de ciertos derechos, como son los que provienen de la Carta Magna o aquellos otros que derivan de la propia vida en prisión; el disfrute y el acceso a ellos puede verse limitado o incluso eliminado en función de lo que se recoja en la sentencia o en función de lo establecido en la Ley Orgánica General Penitenciaria y en el Reglamento de su desarrollo.

Los derechos que traen causa en el marco normativo de la propia Constitución Española son, entre otros, el derecho a la vida e integridad física y moral, el cual dada su importancia, está situado en el título primero -derechos y deberes fundamentales-, dentro del capítulo segundo, sección primera -derechos fundamentales y libertades públicas-, artículo $15,{ }^{12}$ y es la Ley Orgánica General Penitenciaria la que se hace eco del mismo en su articulado, artículos 3-4 y $6^{13}$, así como el Reglamento Penitenciario, artículo 4-2 ${ }^{14}$. En referencia a esto, al estar sujeto el recluso a un modo de interrelación suyo con el funcionariado de prisiones y a más a más con la propia Administración Penitenciaria, deben garantizarse estos derechos.

${ }^{11}$ MANZANOS BILBAO, C., «Salir de prisión: la otra condena», Revista de Servicios Sociales, $\mathrm{N}^{\mathrm{0}} 35,(1998) 65$ y 66.

${ }^{12}$ Art. 15 CE: "Todos tienen derecho a la vida y a la integridad física y moral, sin que, en ningún caso, puedan ser sometidos a tortura ni a pena o tratos inhumanos o degradantes".

${ }^{13}$ Art. 3-4 LOGP: "La Administración penitenciaria velará por la vida, integridad y salud de los internos".

Art. 6 LOGP: "Ningún interno será sometido a malos tratos de palabra u obra".

${ }^{14}$ Art. 4-2 RP: "a) Derecho a que la Administración penitenciaria vele por sus vidas, su integridad y su salud, sin que puedan, en ningún caso, ser sometidos a torturas, a malos tratos de palabra o de obra, ni ser objeto de un rigor innecesario en la aplicación de las normas". 
En línea con esto, hay que referirse también al riesgo que padece la integridad física de los funcionarios de prisiones por las agresiones que vienen sufriendo de forma constante en el ejercicio de su profesión ${ }^{15}$. De tal manera que, la Asociación Profesional de Funcionarios de Prisiones da visibilidad al hecho que en España se perpetra aproximadamente una agresión a funcionarios de prisiones cada tres días por parte de reclusos. Según explica Francisco Llamazares, presidente de esta asociación, el nexo causal de este tipo de acciones es la falta de personal y de medios así como también se le une el incremento de internos con patologías psiquiátricas, sin olvidar la falta formación para manejar situaciones de altercados por parte de este colectivo de funcionarios. A esta realidad se suma que muchos funcionarios de prisiones no denuncian las agresiones porque al existir un protocolo para aplicar en estos casos, el mismo sirve para analizar la actuación del funcionario/s que se hayan visto envueltos en una situación de este tipo, y ante el temor de ser sancionados, se retraen y se abstienen de denunciar. A continuación se recoge en una gráfica el índice de agresiones al funcionariado de prisiones en centros penitenciarios españoles, de mayor a menor, y en la horquilla que va desde el año 2004 hasta mayo del año 2020, conforme a datos oficiales según lo explicado por la Asociación Profesional de Funcionarios de Prisiones; estas cifras son: Córdoba 352 agresiones, Valencia 303 agresiones, Madrid V Soto del Real 281 agresiones, Mallorca VII 228 agresiones, Madrid Estremera 212 agresiones, Albolote Granada 200 agresiones, Algeciras 199 agresiones, Puerto III Cádiz 188 agresiones, Zuera Zaragoza 175 agresiones, Texeiro La Coruña 169 agresiones.

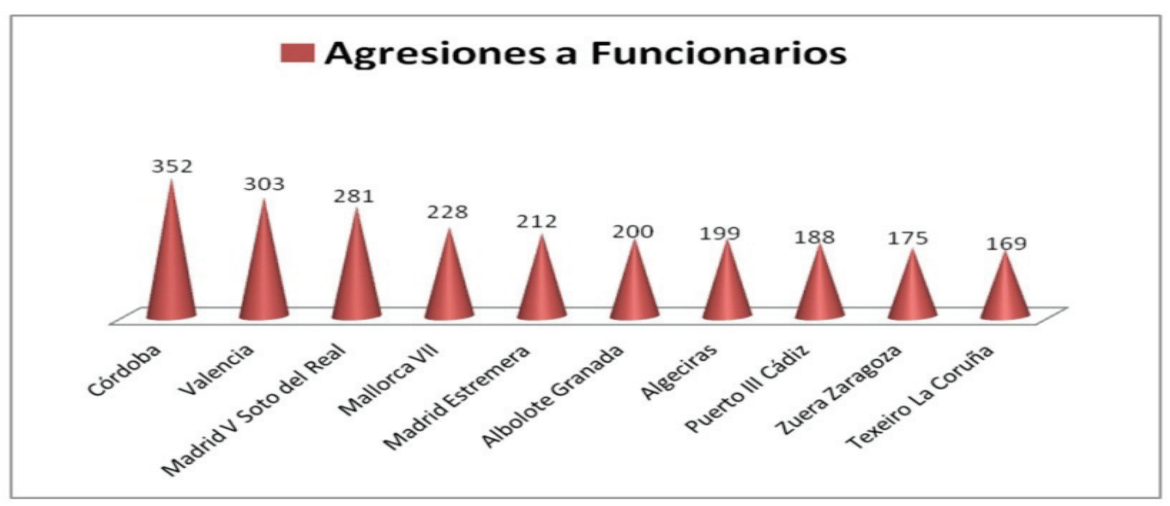

Figura 1.

Fuente: elaboración propia

${ }^{15}$ MORENO, R., «La APFP denuncia que en España se produce una agresión cada tres días a funcionarios de prisiones», en Confilegal, 07-07-2020,

https://www.bing.com/search?q=APFP+denuncia+agresiones $+07 \% 2 \mathrm{~F} 07 \% 2 \mathrm{~F} 2020+$ confil egal + rosalina + moreno \&cvid $=43847$ ee3d4e94893857dbd91aa45d123\&aqs=edge..69i57.2793 1j0j1\&pglt=643\&FORM=ANSPA1\&PC=LCTS; consultado: 27-08-2021. 
Otro asunto que está inmerso en este derecho a la vida e integridad física y moral del recluso, es proporcionarle asistencia médica obligatoria cuando se crea una situación de peligro para esta persona, y en esta dirección hay pronunciamiento del Tribunal Constitucional ${ }^{16}$.

Otro derecho al amparo de la Constitución Española de aplicación en las prisiones, que a priori podría parecer incongruente en este ámbito, es el derecho a la libertad ${ }^{17}$, y se trata del tiempo máximo de detención de una persona cuando no existe mandamiento judicial que autorice su permanencia en prisión y son setenta y dos horas, así como también que el tiempo máximo de permanencia en prisión provisional se hará a través de ley.

Me voy a referir, someramente, a aquellos derechos ${ }^{18}$ que traen causa en la figura del interno como persona que se encuentra cumpliendo condena en prisión, y a propósito de esto, tanto la Ley Orgánica General Penitenciaria como el Reglamento Penitenciario los contemplan en su articulado, y son, entre otros, el derecho a que el recluso esté destinado en un establecimiento penitenciario que esté en consonancia con el grado en el que está clasificado puesto que a cada grado le es de aplicación un sistema de cumplimiento y de vida distinto. Otro de estos derechos que amparan a un recluso y que es además el inicio de su vida carcelaria, es el derecho a que se les informe sobre sus derechos y obligaciones, de los cauces que tienen para tramitar reclamaciones y demás quejas.

Por lo que antecede y como broche final resta añadir, que las prisiones en España han tenido una destacada evolución desde hace siglos, y esto no puede

16 STC 137/1990, de 19 de julio: “.....la asistencia médica obligatoria autorizada por la resolución judicial objeto del recurso de amparo no vulnera ninguno de los derechos fundamentales invocados por los demandantes, constituyendo tan sólo una limitación del derecho a la integridad física y moral garantizada por el art. 15 de la Constitución, y unida ineludiblemente a ella una restricción a la libertad física, que vienen justificadas en la necesidad de preservar el bien de la vida humana, constitucionalmente protegido, y que se realiza mediante un ponderado juicio de proporcionalidad, en cuanto entraña el mínimo sacrificio del derecho que exige la situación en que se hallan aquéllos respecto de los cuales se autoriza".

${ }^{17}$ Art. 17-4 CE: "La ley regulará un procedimiento de "habeas corpus" para producir la inmediata puesta a disposición judicial de toda persona detenida ilegalmente. Asimismo, por ley se determinará el plazo máximo de duración de la prisión provisional".

Art. 17-2 LOGP: "Los detenidos serán puestos en libertad por el Director del establecimiento si, transcurridas las setenta y dos horas siguientes al momento del ingreso, no se hubiere recibido mandamiento u orden de prisión".

Art. 23-1 RP: "Cuando no se hubiere recibido orden o mandamiento de libertad o de prisión expedido por la autoridad competente, los detenidos serán excarcelados por el Director del establecimiento o quien reglamentariamente le sustituya, al vencimiento del plazo máximo de detención o transcurridas las setenta y dos horas siguientes al momento del ingreso".

${ }^{18}$ DE VICENTE MARTINEZ, R. et al., Derecho Penitenciario, Valencia, Edit. Tirant lo Blanch, 2015, pp. 70 a 73. 
parar puesto que los delitos y el perfil de los delincuentes también lo han hecho, y hay que dar respuesta normativa y de funcionamiento a las nuevas realidades sociales que se trasladan de la calle al interior de las prisiones. La especialización delictiva y el aumento progresivo de diferentes perfiles de delincuentes requieren que estas transformaciones sean resueltas para que la reinserción alcance más y mejores cotas de éxito.

\section{REFERENCIAS BIBLIOGRÁFICAS Y OTRAS FUENTES}

- CERVElló DONDERIS, V., Derecho Penitenciario, Valencia, Edit. Tirant lo Blanch, 2016, pp. 250-253.

- DE VICENTE MARTíNEZ, R. et al., Derecho Penitenciario, Valencia, Edit. Tirant lo Blanch, 2015, pp. 296 y 297.

- FERNÁNDEZ RODRÍGUEZ, M.D., El pensamiento penitenciario y criminológico de Rafael Salillas, Santiago de Compostela, Secretariado de Publicaciones de la Universidad de Santiago de Compostela, 1976, pp. 206 y ss.

- FERNÁNDEZ BERMEJO, D., Individualización científica y tratamiento en prisión, Madrid, Gobierno de España -Ministerio del Interior- Secretaría General de Instituciones Penitenciarias, 2013, pp. 478 y ss.

- GARCÍA VALDÉS, C., «Derecho Penitenciario Militar: una aproximación histórica», en Anuario de Derecho Penal y Ciencias Penales, Tomo 39, Fasc 3 (1986) 774 y ss.

- MANZANOS BILBAO, C., «Salir de prisión: la otra condena», en Revista de Servicios Sociales, No 35 (1998) 65 y 66.

- MORENO, R., «La APFP denuncia que en España se produce una agresión cada tres días a funcionarios de prisiones», en Confilegal, 07-07-2020:

https://www.bing.com/search?q=APFP+denuncia+agresiones $+07 \% 2 \mathrm{~F} 07 \%$ 2 F2020 + confilegal + rosalina + moreno\&cvid $=43847$ ee $3 d 4$ e94893857dbd9 1 aa45d123\&aqs=edge..69i57.27931j0j1\&pglt=643\&FORM=ANSPA $1 \& P C$ =LCTS; consulta: 27-08-2021.

- RÍOS MARTÍN, J.C., «Los ficheros de internos de especial seguimiento», en Cuadernos de Derecho Penitenciario (Colegio de Abogados de Madrid), $\mathrm{N}^{\mathrm{o}} 3$ (1998). 
- SERRANO PATIÑO, J. V., «Una reflexión histórica desde una perspectiva penitenciaria» [en línea], Estudios de Historia de España 17, 2015. Disponible en:

http://bibliotecadigital.uca.edu.ar/repositorio/revistas/reflexion-historicaperspectiva-penitenciaria.pdf; consultado: 08-12-2020.

- SOLAR CALVO, P., «Límites al fichero FIES en la nueva LOPD: una oportunidad para el cambio», en Legal Today, Portal Jurídico de Thomson Reuters, 15-03-201: Límites al fichero FIES en la nueva LOPD: una oportunidad para el cambio -Información jurídica, noticias y artículos- Legal Today; consultado: 11-12-2020. 